\title{
A Dual Series DC to DC Resonant Converter
}

\author{
V.Balaji, Yadav Srujana Choppari, K Srinivas
}

\begin{abstract}
A development of twofold thunderous DC-DC converter with zero voltage exchanging (ZVS) and 0 modern replacing (ZCS) highlights proposed on this paper. This topology contains of switches and capacitors clips at the crucial facet of the disengagement transformer. Two switches are labored in a reciprocal way underneath a heartbeat width tweak (PWM) conspire.

The auxiliary facet of the transformer related to the heap thru association resounding circuit and a redressing diode half of-join arrange, where here and there the inclines of the diode cuttingedge is constrained with the aid of the slant of the current in the full circuit, bringing approximately reduced exchanging misfortunes within the diodes. Two arrangement thunderous circuit giving pressure circulate to the yield load without interruption over the tremendous and poor cycles of pastime. This demonstrates the yield voltage of the converter proposed may be set making use of either the manipulate beat width law or recurrence stability control. The next advance down and step-up voltage alternate may be performed utilising the proposed topology.
\end{abstract}

Watchwords - PWM, resounding, Capacitor Clamping, separating transformer, Series Resonant, Voltage Conversion

\section{INTRODUCTION}

DC to DC manipulate converters anticipate a considerable activity in some packages consisting of DC manage dissemination frameworks, sustainable electricity source age advancements, and DC exchanging elements modepower.

In the advancement of latest topologies and control plans is constantly a non-stop take a look at for specialists. The motivation behind this take a look at is the improved proficiency, improved power thickness, diminishing the multifaceted nature of the manage plan, and lowering absolute fee of production of converters. A noteworthy development inside the strategy for delicate exchanging, which includes a 0 voltage replacing (ZVS) and zero modern replacing (ZCS) processes, have empowered DCDC converter to be labored at a excessive converting recurrence to diminish replacing misfortunes.

\section{TECHNIQUE FOR EXISTING}

A few endeavors were made to construct the electricity thickness of clipped resounding converter. Interleaving procedure is one of the proposed strategies understood to construct the electricity moved to the heap and reduce information and yield swell flows on top of things element treatment circuits. In this approach, an indistinguishable unit parallel converter and worked at a similar changing

Revised Manuscript Received on September 14, 2019.

V.Balaji, Professor, Department of EEE, JNN Institute of Engineering, Chennai, Tamilnadu, India.

Yadav Srujana Choppari, Assist. Prof, Department of EEE, Siddhartha Institute of Technology \& Sciences, Narapally, Ghatkesar, Hyderabad, Telangana, India.

K Srinivas, Assist. Prof, Department of EEE, Siddhartha Institute of Technology \& Sciences, Narapally, Ghatkesar, Hyderabad, Telangana, India. recurrence but with a level moved sign transfer. Regardless of the expansion in control is moved to the heap, this methodology introduced approximately an increment in the quantity of replacing and aloof parts, increased refinement in changing plan, just as increased era fees. For instance, degree 2 dynamic caught clasps resounding converter, which give nonstop energy move to the heap yield throughout complete cycle pastime. Nonetheless, two times that of dynamic and uninvolved segments don't essentially extend control thickness converters.

\section{PROPOSED METHOD}

Dynamic topology alternatives clasp full DC-DC converter is proposed. By applying arrangement resounding circuit, the alternate of potential to the heap yield isn't interfered with, for this reason expanding the energy move potential. The proposed converter, alluded to as double arrangement resounding DC-DC converter, ZVS and ZCS condition includes on an collection of operating changing recurrence and yield voltage range.

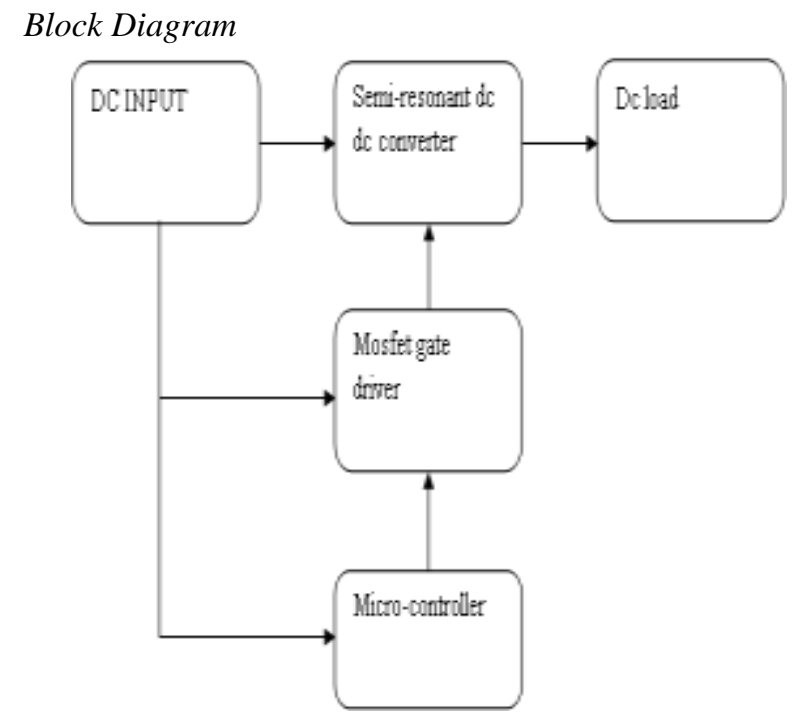

Fig1.Functional block diagram

\section{Description}

Functional block diagram given above. blocks explains that the DC voltage is given as input to a resonant dc to $\mathrm{dc}$ converter as a resonance spring. A PIC microcontroller is used to generate high speed PWM to control the transformer switch

\section{Simulation Circuit}




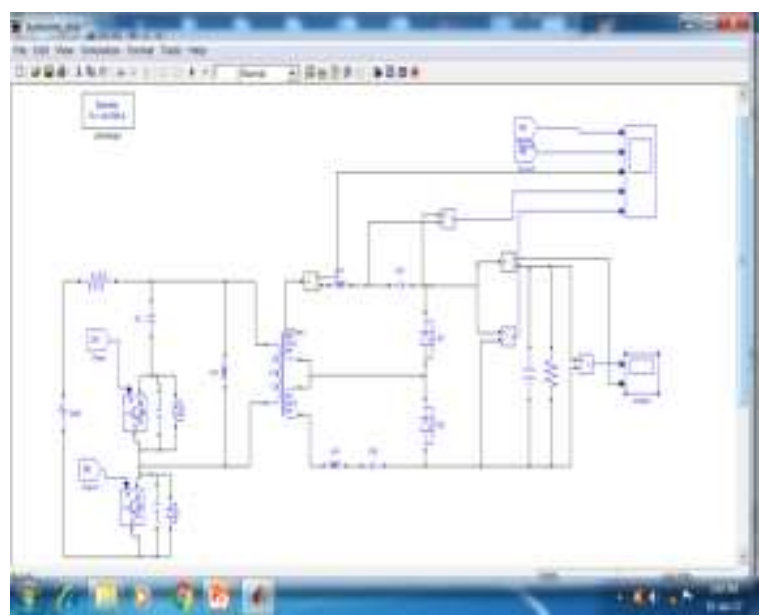

Fig2. Simulation Output

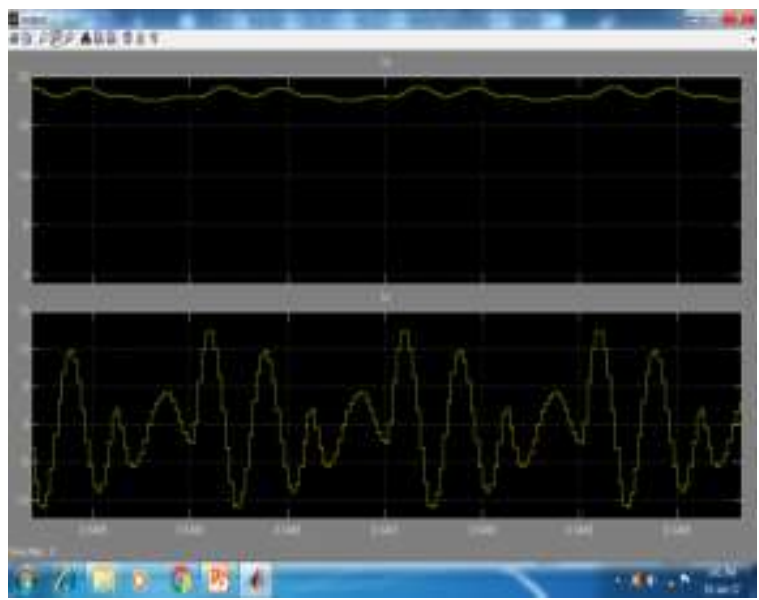

Fig3. Simulation Waveform

Hardware Circuit Diagram
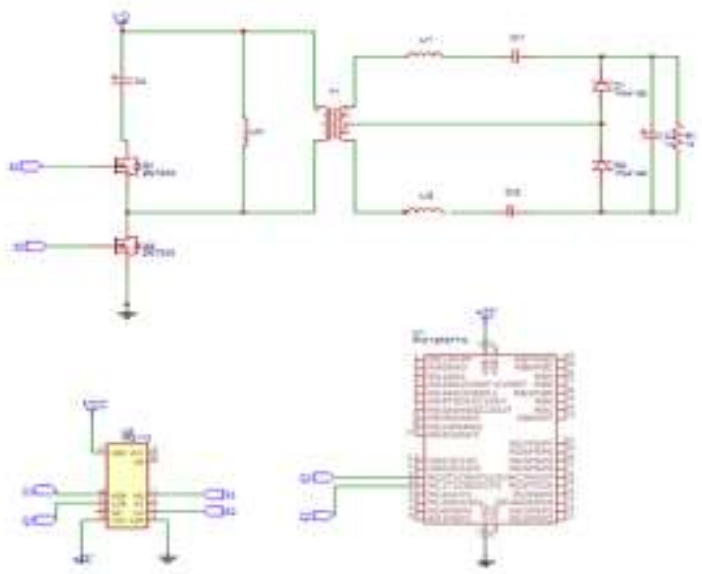

Fig4.Hardware Circuit Diagram

\section{Microcontroller}

\section{PIC16F877A}

PIC microcontroller PIC16F877 microcontroller is one of the maximum popular inside the enterprise. The controller is surely agreeable to make use of, coding or programming of the controller is likewise easier. One of the primary favorable occasions is that it tends to be compose get rid of but tons as may be expected in mild of the reality that it makes use of FLASH reminiscence innovation. He has an combination of forty pins and there are 33 pins for data and yield. PIC16F877 microcontroller is utilized in severa ventures. PIC16F877 likewise has severa programs in computerized digital circuits.

\section{Gadget OVERVIEW}

This file includes facts approximately a specific device on the accompanying devices:

\section{PIC16F877}

PIC16F873A/876A gadgets are just available in 28-stick bundles, while PIC16F874A/877A gadgets are handy in 40stick and 44-stick package. All devices inside the own family PIC16F87XA regular gives design with the accompanying contrasts:

The PIC16F873A and PIC16F874A have one-portion of the aggregate on-chip memory of the PIC16F876A and PIC16F877A.

The gadget has three 28 -stick I/O port, at the same time as the system $40 /$ forty four-stick has five.

28-stick gadgets have fourteen interferences, at the same time as the system $40 /$ forty four-stick has fifteen.

28 -stick gadgets have five channels $\mathrm{A} / \mathrm{D}$ enter, even as the device 40/44-stick has 8 .

The Parallel Slave Port is actualized uniquely at the gadget forty/44-stick.

\section{DRIVER IR2110}

IR2110/IR2113 is a excessive voltage, rapid energy MOSFET and IGBT driver with self reliant high and facet referenced yield channels is low. Restrictive HVIC and lock resistant CMOS improvements empower ruggedized solid improvement. Input motive ideal with fashionable CMOS or LSTTL yields, down to $3.3 \mathrm{~V}$ rationale. Yield drivers encompass a excessive heartbeat ebb and flow cradle set up intended for least motive force cross-conduction. Proliferation delays are coordinated to improve use in high recurrence applications. Skimming channel can be utilized to pressure a N-direct MOSFET or IGBT within the highaspect association operating as much as 500 or six hundred volts.

\section{Highlights}

Gliding channel supposed for bootstrap pastime Fully operational to $+500 \mathrm{~V}$ or $+600 \mathrm{~V}$ Tolerant terrible voltage brief $\mathrm{dV} / \mathrm{dt}$ immune.Gate force deliver run from 10 to $20 \mathrm{~V}$.Under voltage lockout for the two channels.

Three.3V ideal purpose separate motive deliver scope of $3.3 \mathrm{~V}$ to $20 \mathrm{~V}$ Logic and power ground offset.CMOS $\pm 5 \mathrm{~V}$ contribution with pull-down.Cycle Schmitt-activated via the belief of the cycle of area-activated logic.Matched proliferation delay for each channels.Outputs in levels with enter. 


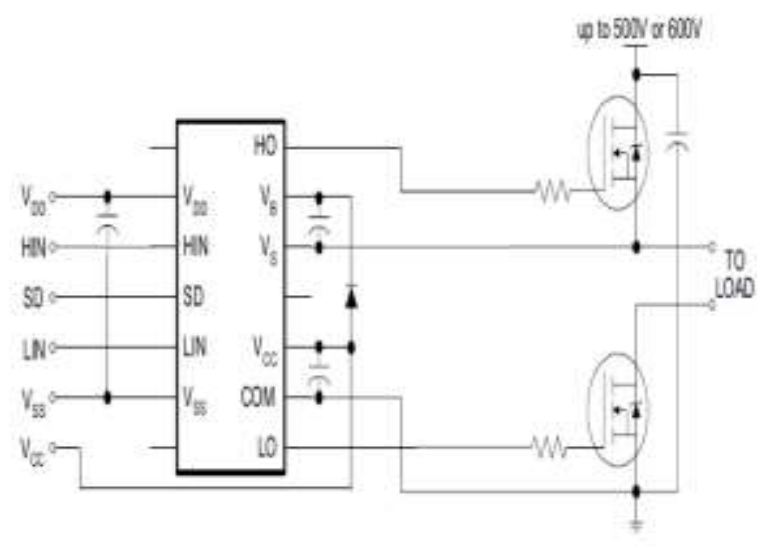

Fig5.Circuit Connection Diagram

Functional block diagram

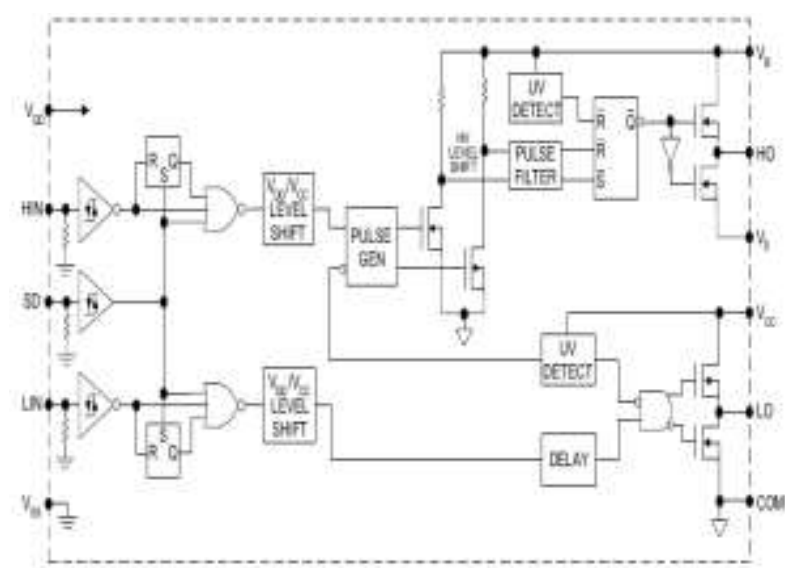

Fig6.Functional block diagram of IR2110

$4 N 60$

4A, 60OV N-CHANNEL POWER MOSFET

UTC 4 N60 is over the top electrical voltage MOSFET and is intended to have a higher qualities, including quick exchanging time, low door level, low-opposition on-state and misrepresented highlights rough torrential slide attributes. This vitality MOSFETs commonly utilized in rapid exchanging applications in vitality materials, green engine control PWM DC to DC converter over-burden and extension circuits.

Highlights AND SYMBOL

- RDS $(\mathrm{ON})<2.5 \omega @ \mathrm{VGS}=10 \mathrm{~V}, \mathrm{ID}=2.2 \mathrm{a}$

- Fast Switching Capability

- Avalanche Energy Specified

- Improved dv/dt capacity, high roughness.

\section{SYMBOL}

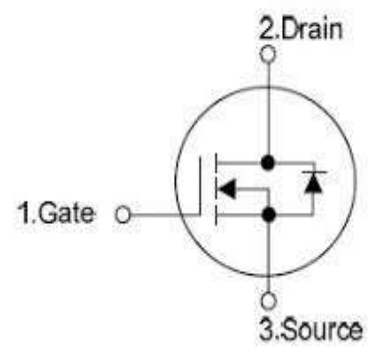

Fig7.Symbol of MOSFET

Classifications Of Resonant

The resonant converter comprehensively classified into eight sorts. That is:-
1. Arrangement resonant inverter

2. parallel resonant inverter

3. Class E Resonant Converter

4. Class E Resonant Rectifier

5. Zero Voltage Switching (ZVS) Resonant Converter

6. Zero Current Switching (ZCS) Resonant Converter

7. Two Quadrant ZVS Resonant Converter

8 . The thunder inverter dc-connect

Zero Voltage Switching (Zvs) Resonant Converter

1. ZVS resonant converter turn on and off at zero voltage.

2.Output voltage control can be achieved by shifting the recurrence and working with steady control of the off time.

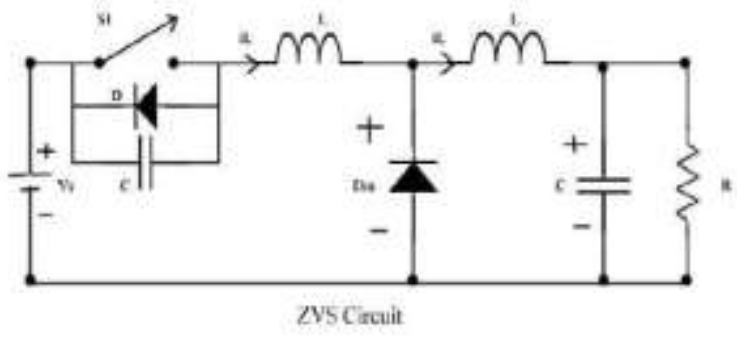

Fig8. ZVS Resonant Converter

Zero Current Switching(Zcs) Resonant Converter

- Zero Current Switching(ZCS) Resonant Converter turn On \& turn off at zero current.

- This converter can operate at higher range frequency that is $1 \mathrm{MHz}$ to $2 \mathrm{Mhz}$.

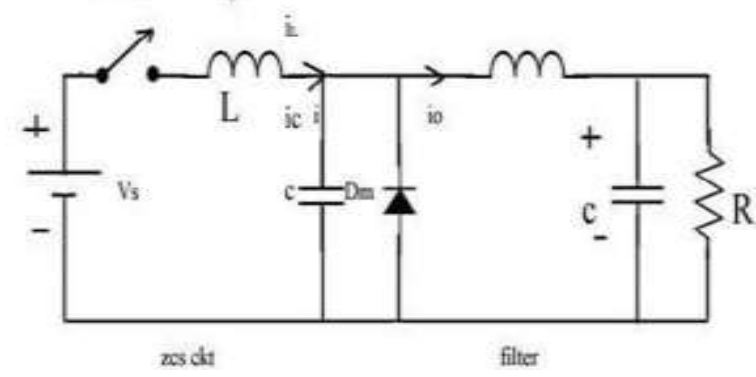

FIG9. (ZCS) Resonant Converter

\section{PROPOSED TOPOLOGY \& RESULTS}

The proposed topology of the dual series-resonant DCDC converter is shown in Figure.

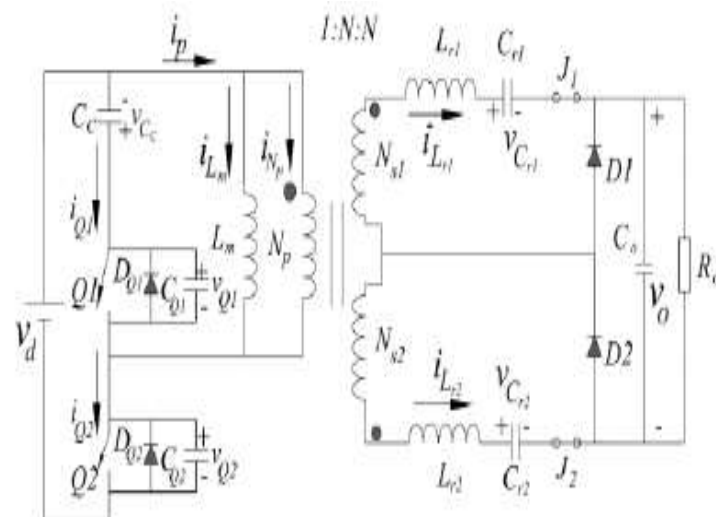

Fig10. Proposed Dual Series DC to DC Resonant Convertere

Published By: 
On the vital aspect of the segregation transformer comprises of a twisting round Npand charging inductance Lm. Arrangement circuit at the contribution of the transformer incorporates of dynamic switches, 1.Q1 and a pair of.Q2, and cinch capacitor Cc Q1.The association with in opposition to parallel diode and inner capacitor transfer (DQ1, CQ1, DQ2, and CQ2) is regarded in Figure10, The auxiliary aspect of the transformer has windings (NS1 and NS2), each associated with isolated but indistinguishable arrangement complete circuit with parameters which might be indistinguishable (ie, LR1 and CR1 to NS1, LR2 and $\mathrm{CR} 2$ for NS2, with LR1 = LR2, CR1 = CR2 and NS1 = NS2 = NS).

Two jumper shunt ( $\mathrm{J} 1$ and $\mathrm{J} 2$ ) are remembered for the circuit. By evacuating one of the jumpers, the topology can be modified to a solitary thunderous association circuit to allow correlation of consequences between the arrangement resounding topology single and distinctive arrangement complete topology. A segment correcting diode (D1 and D2) associating the yield load and yield capacitor for the arrangement thunderous circuit. Positive extremity of all voltage and modern elements regarded in Figure10.

Photography Of Hardware

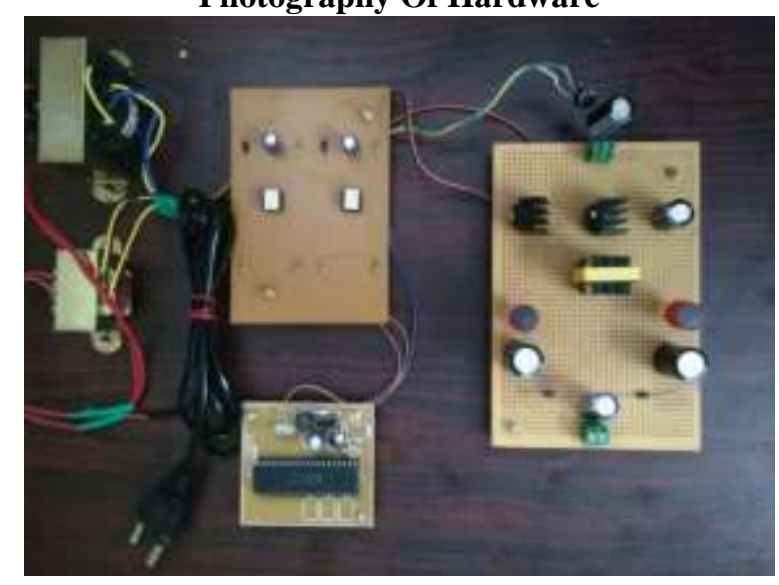

\section{CONCLUSION}

Dynamic topology options clasp resounding DC-DC converter which makes use of numerous association thunderous topology is proposed. The second arrangement thunderous circuit is indistinguishable at the auxiliary aspect of the converter offers a corresponding manner to supplying contemporary to the heap without interference in the course of complete operational mode converter, on this way expanding the yield control flow capacity of the converter. It includes a zero voltage flip-on for the switch and 0 current flip-on for the yield diode, where the ascent and fall of the slant while the diode contemporary is confined via the slant of the resounding circuit. The effects of the trial model topology show first rate expertise proposed with reenactment and displaying effects.

\section{REFERENCE}

1. R. D. Middlebrook, S. Cuk, "A Unified Approach Modeling General Switching Converter Power Stage," 1976 IEEE Power Electronics Specialists Conf., 1976, p. 18-34.

2. Y. K. Lo, J. Y. Lin, "Dynamic Clamping ZVS Flyback Converter Employing Two Transformers," IEEE Trans. Power Electron., Vol 22, no. 6, pp. 2416-2423, 2007.
3. U. R. Prasanna, A. K. Rathore, "Little Signal Modeling of dynamic clasp ZVS now-Fed Full-Bridge Isolated DC/DC Converter and Control System Implementation Using PSoC," IEEE Trans. Ind. Electron., Vol. Sixty one, no. 3, pp. 1253-1261, March 2014.

4. H. Wang, S. Dusmez, and A. Khaligh, "Plan Considerations for Level-2 On-Board Charger Based PEV Interleaved Boost PFC and LLC Resonant Converters," Transportation Electrification Conf. What's more, Expo. (ITEC), June 2013, p. 1-8.

5. E. X. Yang, F. C. Lee, and M. M. Jovanovic, "Little sign demonstrating of the electronic circuits of depth with the aid of the all-inclusive concept of potential clarifies," Proc. VPEC Seminar, 1991, p. 167-178.

6. B. R. Lin, C. L. Huang, "Interleaved ZVS Converter With Current Ripple Cancellation," IEEE Trans. Ind. Electron., Vol. Fifty five, no. 4, April 2008.

7. M. E. Elbuluk, G. C. Verghese, and J. G. Kassakian, "displaying take a look at facts and automatic manage resounding converter," IEEE Trans. Power Electron. Vol. 3, no. Three, pp. 344-354, July 1988.

8. G. Jun-yin, Hong-fei W., C. Guo-cheng, and X. Yan, "Exploration onphotovoltaic framework related inverter based delicate replacing converter interleavedflyback," in Proc. IEEE Conf. Ind. Electron. Appl. (ICIEA), 2010, pp. 1209-1214. 